\title{
The role of intersystem crossing in the deactivation of the singlet excited aminofluorenones
}

\author{
László Biczók, ${ }^{* a}$ Tibor Bérces, ${ }^{a}$ Tomoyuki Yatsuhashi, $\dagger^{b}$ Hiroshi Tachibana ${ }^{b}$ and Haruo Inoue ${ }^{b}$ \\ ${ }^{a}$ Chemical Research Center, Hungarian Academy of Sciences, P.O. Box 17, 1525 Budapest, \\ Hungary.E-mail:biczok@chemres.hu \\ ${ }^{b}$ Department of Applied Chemistry, Graduate Course of Engineering, Tokyo Metropolitan \\ University: CREST, Japan Science and Technology, 1-1 Minami-ohsawa, Hachioji, \\ Tokyo 192-0397, Japan
}

Received 8th December 2000, Accepted 19th January 2001

First published as an Advance Article on the web 22nd February 2001

\begin{abstract}
Solvent and substituent effects on the competition between internal conversion and triplet formation were studied systematically for aminofluorenones and their $N$-methylated derivatives. Intersystem crossing (ISC) was found to be the dominant process for the singlet excited 1-amino- and 1-methylaminofluorenone in all solvents. The short fluorescence decay time of these compounds does not originate from intramolecular hydrogen bonding induced internal conversion but it is due to the fast triplet formation. Rather slow $\left(k_{\mathrm{ISC}} \leqslant 4.8 \times 10^{7} \mathrm{~s}^{-1}\right)$ and solvent insensitive intersystem crossing characterizes the photophysical behavior of 2-, 3- and 4-aminofluorenones but their internal conversion rate strongly increases with solvent polarity. The change of the internal conversion rate constants with molecular structure and solvent can be rationalized in terms of the energy gap law.
\end{abstract}

\section{Introduction}

One of the greatest challenges in photophysical research is to relate the luminescence properties to molecular structure. The photophysical properties of fluorenone derivatives have received widespread interest for decades because their fluorescent behavior $^{1-4}$ as well as the quantum yields of their photophysical process ${ }^{5-7}$ are very sensitive to solvent polarity, substitution ${ }^{8}$ and temperature change. ${ }^{9,10} 3$-Aminofluorenone was successfully utilized to establish a polarity scale for electrolyte solutions in organic media, ${ }^{11,12}$ whereas the unsubstituted singlet excited fluorenone was shown to be a unique molecular probe which is able to distinguish between the hydrogen bonding interaction with its microenvironment and the effect of bulk polarity. ${ }^{13,14}$

Recent work demonstrated that fluorenones are excellent model compounds for the study of the intermolecular hydrogen bonding induced deactivation and revealed the major details of the excited state quenching processes. ${ }^{15-18}$ However, it is still not clear if intramolecular hydrogen bonding influences the photophysical processes occurring from the singlet excited state of 1-aminofluorenone. The fluorescent characteristics of this compound exhibit a peculiar solvent dependence. ${ }^{19}$ The nonradiative rate constant decreases with increasing solvent polarity and is lower in protic solvents than in aprotics. To rationalize these observations Moog et al. concluded that intramolecular hydrogen bonding between the $\mathrm{N}-\mathrm{H}$ and the carbonyl oxygen in the excited state of 1-aminofluorenone results in a more efficient deactivation pathway than the intermolecular hydrogen bonding with alcohols. ${ }^{19}$ As an extension of this work, Thompson et al. proposed that the electrolyte effect on the photophysical properties of 1-aminofluorenone can be attributed to the disruption of the intramolecular hydrogen bond by the cations. ${ }^{20} \mathrm{~A}$ recent systematic study on the four structural isomers of aminofluorenones and their $N$-methylated

$\dagger$ Present address: Osaka University, Department of Chemistry, 3-3138 Sugimoto, Sumiyoshi, 558-8585 Osaka, Japan. derivatives, however, indicated that intramolecular hydrogen bonding may not control the fluorescent behavior of 1aminofluorenones. $^{21}$

The main goal of the present paper is to obtain deeper insight into the major factors governing the rate of nonradiative deactivation. Special attention is paid to the role of intersystem crossing in the energy dissipation process. We study the effect of the solvent-solute interaction and the substitution at the different sites of the molecule on the rate of internal conversion and triplet formation. In addition, we examine how the variation of molecular structure influences the phosphorescence and the energy of the lowest triplet state. The formulas of the investigated compounds are presented in Fig. 1.

\section{Experimental}

Aminofluorenone derivatives were obtained from sources described in a previous publication. ${ }^{21}$ HPLC grade solvents (Merck) were used without further purification. Samples were deoxygenated using freeze-pump-thaw cycles and then were sealed under vacuum. Triplet-triplet absorption measurements and quantum yield determinations were carried out by $\mathrm{XeCl}$ excimer laser flash photolysis technique as previously described. ${ }^{10,18}$ Fluorescence and phosphorescence measurements were made on a Hitachi F-4010 spectrometer. Fluorescence lifetimes were measured with an Applied Photophysics SP-3 time-correlated single-photon counting apparatus. Further experimental details have already been reported. ${ }^{18,21}$

\section{Results and discussion}

\subsection{Triplet spectra}

Laser flash photolysis of aminofluorenones in toluene gave a short-lived species with absorption built up within the duration of the laser pulse. The transient decayed on the microsecond time scale. Triplet absorption spectra, recorded after the complete decay of the fluorescence signal, are presented in Fig. 2 for three aminofluorenone isomers in toluene. The spectra are not corrected for the ground state absorption. In 
<smiles>[R]c1cccc2c1C(=O)c1ccccc1-2</smiles>

R-

$\mathrm{NH}_{2}-$

$\mathrm{CH}_{3} \mathrm{NH}-$

$1 \mathrm{AF}$

$\left(\mathrm{CH}_{3}\right)_{2} \mathrm{~N}-$

$1 \mathrm{MAF}$

IDMAF<smiles>[R]c1ccc2c(c1)-c1ccccc1C2=O</smiles>

R-

$\mathrm{NH}_{2-}$

$\mathrm{CH}_{3} \mathrm{NH}-$

$3 \mathrm{AF}$

$\left(\mathrm{CH}_{3}\right)_{2} \mathrm{~N}-$

3MAF

3DMAF

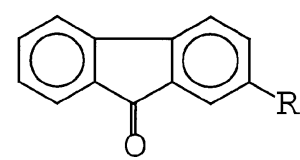

R-

$\mathrm{NH}_{2}-$

$\mathrm{CH}_{3} \mathrm{NH}-$

2AF

2MAF

$\left(\mathrm{CH}_{3}\right)_{2} \mathrm{~N}-$ 2DMAF<smiles>[R]c1cccc2c1-c1ccccc1C2=O</smiles>

$\mathrm{R}-$

$\mathrm{NH}_{2}-$

$\mathrm{CH}_{3} \mathrm{NH}-$

$\left(\mathrm{CH}_{3}\right)_{2} \mathrm{~N}-$

$4 \mathrm{AF}$

4MAF

4DMAF

Fig. 1 Formulas of the investigated compounds.

the case of 2-aminofluorenone, measurable signal was obtained only in less polar solvents than toluene, therefore, the transient absorption spectrum for that compound is given in hexane. These spectra were assigned to triplet-triplet absorption based on the following arguments: (i) in the presence of oxygen the transients were quenched; (ii) addition of perylene shortened the decay time of the transient and concomitant formation of triplet perylene was observed (vide infra).

Comparing the spectra, it is apparent that the triplet-triplet absorption spectrum of the 1-amino derivative is entirely different from that of the other structural isomers. In the former case, significant bleaching can be observed in the 400-445 nm spectral range, which corresponds to the strong visible band in the ground state absorption spectrum. However, no bleaching occurs for the rest of the compounds because the molar absorption coefficient of the ground state in the first absorption band is significantly lower. ${ }^{21}$ Methylation of the amino group does not affect significantly the shape of the triplettriplet absorption spectra, however, it reduces the extent of transient absorption. A particularly large decrease is found in the case of 1-substituted compounds, where the dimethyl-

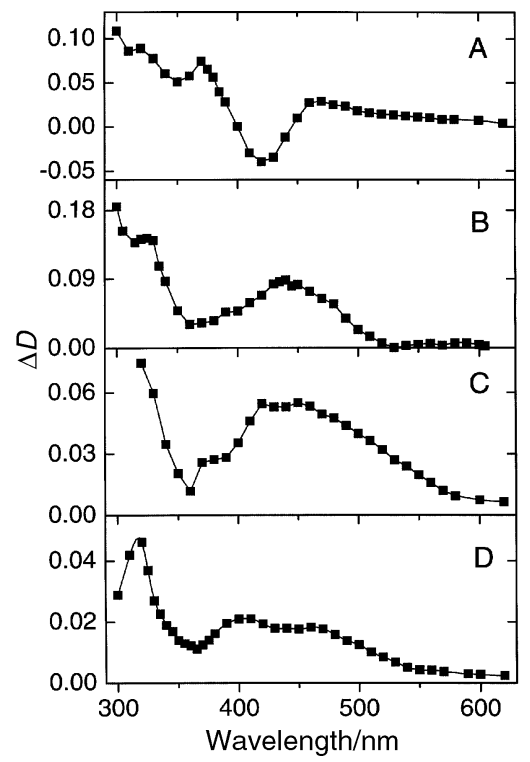

Fig. 2 Triplet-triplet absorption spectra of $1 \mathrm{AF}(\mathrm{A}), 3 \mathrm{AF}(\mathrm{C}), 4 \mathrm{AF}$ (D) in toluene and $2 \mathrm{AF}$ (B) in hexane. amino derivative does not show any triplet-triplet absorption at $295 \mathrm{~K}$.

\subsection{Phosphorescence spectra}

No emission from triplet fluorenones can be detected at room temperature. However, 1- and 3-aminofluorenones phosphoresce in rigid organic glasses. Fig. 3 present phosphorescence, fluorescence and excitation spectra for $1 \mathrm{AF}$ and $3 \mathrm{AF}$ in 2methyltetrahydrofuran at $77 \mathrm{~K}$. The spectra of the methylated derivatives are similar to those plotted in Fig. 3. As it is expected, the excitation spectra of the phosphorescence agree with those of the fluorescence and correspond to the absorption spectra. The shape of the phosphorescence bands is totally different from the structured emission of triplet 2nitrofluorenone, which has a well-established $n \pi^{*}$ character, ${ }^{18}$ indicating that the lowest triplet states of aminofluorenones are $\pi \pi^{*}$ type. The estimated energy differences between the vibrational peaks $(\Delta v)$ of the latter compounds are somewhat lower than the $\Delta v=1400 \mathrm{~cm}^{-1}$ value reported for the unsubstituted fluorenone. ${ }^{22}$ Table 1 shows that the introduction of the amino and the methylated amino substituents diminishes the $0-0$ transition energy of fluorescence $(E(0-0))$ to a larger extent than that of phosphorescence. Hence, the energy gap between the first peak of fluorescence and phosphorescence $(\Delta E)$ becomes smaller for aminofluorenones compared with fluorenone. The phosphorescence decays can be fairly well fitted by assuming first-order kinetics and the lifetimes $\left(\tau_{\mathrm{P}}\right)$ are in the ms range. Attempts to observe phosphorescence for 2- and 4-aminofluorenones failed owing to the low quantum yield $\left(<5 \times 10^{-4}\right)$. The rate constant of phosphorescence is probably very low in these compounds, analogously to that suggested for fluorenone. ${ }^{4}$

\subsection{Energy transfer to perylene}

The addition of increasing amounts $\left(5 \times 10^{-5}-2 \times 10^{-4} \mathrm{M}\right)$ of perylene gradually shortened the lifetime of triplet aminofluorenones, and the growing in of the well-established absorption of triplet perylene at $490 \mathrm{~nm}^{23}$ was observed. The build-up time of the triplet perylene matched the decay time of triplet aminofluorenone and the rate of the energy transfer was diffusion controlled $\left(k_{\mathrm{q}}>3 \times 10^{9} \mathrm{M}^{-1} \mathrm{~s}^{-1}\right)$. In accordance with the results achieved by phosphorescence spectroscopy (vide supra), this observation indicates that the triplet energy for aminofluorenones is higher than that of perylene $\left(12373 \mathrm{~cm}^{-1} \approx 148 \mathrm{~kJ} \mathrm{~mol}^{-1}\right){ }^{23}$

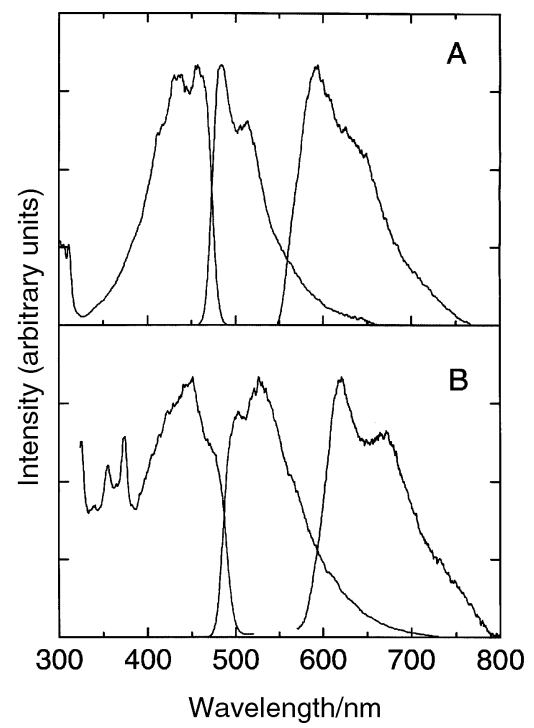

Fig. 3 Excitation, fluorescence and phosphorescence spectra for 1AF (A) and $3 \mathrm{AF}$ (B) in 2-methyltetrahydrofuran glass at $77 \mathrm{~K}$. 
Table 1 Spectral data and phosphoresce decay times in 2-methyltetrahydrofuran at $77 \mathrm{~K}$

\begin{tabular}{|c|c|c|c|c|c|c|c|c|}
\hline & \multicolumn{2}{|c|}{ Phosphorescence } & \multicolumn{2}{|l|}{ Excitation } & \multicolumn{4}{|l|}{ Fluorescence } \\
\hline & $E(0-0) / \mathrm{cm}^{-1}$ & $\Delta v^{a} / \mathrm{cm}^{-1}$ & $E(0-0) / \mathrm{cm}^{-1}$ & $\Delta v^{a} / \mathrm{cm}^{-1}$ & $E(0-0) / \mathrm{cm}^{-1}$ & $\Delta v^{a} / \mathrm{cm}^{-1}$ & $\Delta E^{b} / \mathrm{cm}^{-1}$ & $\tau_{\mathbf{P}} / \mathrm{ms}$ \\
\hline $1 \mathrm{AF}$ & 16880 & 1140 & 21920 & 1150 & 20670 & 1210 & 3790 & 29 \\
\hline 1MAF & 16200 & c & 20900 & 1180 & 19600 & 1100 & 3400 & 23 \\
\hline 1DMAF & 16120 & c & 20860 & 1080 & 19500 & 1010 & 3380 & 22 \\
\hline $3 \mathrm{AF}$ & 16100 & 1200 & 21200 & 1040 & 19870 & 1010 & 3770 & 25 \\
\hline 3MAF & 16220 & 1180 & 21160 & 1100 & 19120 & c & 2900 & 24 \\
\hline 3DMAF & 15930 & 1200 & 21050 & $c$ & 19780 & 1150 & 3850 & 23 \\
\hline $4 \mathrm{AF}$ & $d$ & $d$ & 19610 & 1260 & 18050 & 990 & $d$ & $d$ \\
\hline 4MAF & $d$ & $d$ & 19120 & 1120 & 17640 & $c$ & $d$ & $d$ \\
\hline 4DMAF & d & $d$ & $c$ & $c$ & 17480 & c & $d$ & $d$ \\
\hline Fluorenone $e^{e}$ & $17600^{e}$ & $1400^{e}$ & & & $21900^{e}$ & & 4300 & $1.9^{e}$ \\
\hline
\end{tabular}

${ }^{a}$ Estimated energy difference between the vibrational peaks. ${ }^{b}$ The energy gap between the first peak of fluorescence and phosphorescence. ${ }^{c}$ No vibrational structure. ${ }^{d}$ No phosphorescence. ${ }^{e}$ Ref. 22 , in ethanol.

The efficient triplet sensitization of perylene was exploited to determine the triplet yield of aminofluorenones. A concentration of perylene of $2 \times 10^{-4} \mathrm{M}$ ensured that more than $95 \%$ of the triplet energy donors transferred their energy to perylene. The triplet yields $\left(\Phi_{\text {ISC }}\right)$ were attained from the triplet perylene absorbance at $490 \mathrm{~nm}$ in the solution of aminofluorenones $(A)$ relative to that in the reference solution $\left(A_{\text {ref }}\right)$ which had matched optical density at the laser wavelength $(308 \mathrm{~nm})$.

$$
\Phi_{\text {ISC }}=\left(\Phi_{\text {ISC }}\right)_{\text {ref }}\left(A / A_{\text {ref }}\right)
$$

Because of the low molar absorption coefficient of perylene in the ground state at $308 \mathrm{~nm}$ and the very low triplet yield $\left(\Phi_{\text {ISC }}=0.014\right),{ }^{23}$ an almost negligible amount of triplet perylene was formed via direct excitation. The very small transient absorption arising from the direct excitation of perylene was measured in the absence of sensitizer and it was subtracted from the signals obtained in solutions containing sensitizer. To avoid the error arising from the solvent dependence of the molar absorption coefficient of triplet perylene, both the reference and the compound with unknown triplet yield were measured in the same solvent. Fluorenone in toluene $\left(\left(\Phi_{\mathrm{ISC}}\right)_{\mathrm{ref}}=\right.$ $0.93),{ }^{7}$ benzophenone in acetonitrile $\left(\left(\Phi_{\mathrm{ISC}}\right)_{\text {ref }}=1.00\right)^{23}$ and $N$ methyl-1,8-naphthalimide in ethanol $\left(\left(\Phi_{\text {ISC }}\right)_{\text {ref }}=0.85\right)^{24}$ served as reference. The use of these compounds had the advantage that their slow unimolecular triplet decay could not compete with the energy transfer in the presence of $2 \times 10^{-4} \mathrm{M}$ perylene.

\subsection{Yields of radiationless processes}

Table 2 summarizes the yield of transitions depopulating the singlet excited state of aminofluorenone derivatives, whereas the fluorescence lifetimes $\left(\tau_{\mathrm{F}}\right)$ are given in Table 3 . The fluorescence yields $\left(\Phi_{\mathrm{F}}\right)$ and lifetimes are in good agreement with the published values. ${ }^{21}$ The small differences arise from the fact that the previously reported data were obtained in aerated solutions. To eliminate the effect of oxygen, $\Phi_{\mathrm{F}}$ and $\tau_{\mathrm{F}}$ were re-measured in degassed samples for the present work.

The internal conversion yield $\left(\Phi_{\mathrm{IC}}\right)$ was derived from the measured fluorescence and triplet yields $\left(\Phi_{\text {ISC }}\right)$ :

$$
\Phi_{\mathrm{IC}}=1-\Phi_{\mathrm{F}}-\Phi_{\mathrm{ISC}}
$$

The solvents were chosen to include non-polar, polar aprotic and polar hydrogen bonding media. It is evident from the data in Table 2 that the photophysical properties of $1 \mathrm{AF}$ and $1 \mathrm{MAF}$ are entirely different from those of the other compounds. In the latter cases, the internal conversion is an important deactivation process in toluene and plays an increasing role in polar aprotic solvent, whereas both the fluorescence and intersystem crossing yields become negligible in hydrogen bonding media such as ethanol. However, triplet formation prevails for $1 \mathrm{AF}$ and $1 \mathrm{MAF}$, independently of the solvent. Our results do not support the interpretation of the experimental data published previously in the literature ${ }^{11,19}$ where it was suggested that intramolecular hydrogenbonding-induced deactivation determined the photophysical behavior of $1 \mathrm{AF}$. Since we find that triplet formation is the

\begin{tabular}{|c|c|c|c|c|c|c|c|c|c|}
\hline & \multicolumn{3}{|l|}{ Toluene } & \multicolumn{3}{|l|}{ Acetonitrile } & \multicolumn{3}{|l|}{ Ethanol } \\
\hline & $\Phi_{\mathrm{F}} \times 10^{-3}$ & ${ }^{3} \Phi$ & $\Phi_{\mathrm{IC}}$ & $\Phi_{\mathrm{F}} \times 10^{-3}$ & ${ }^{3} \Phi$ & $\Phi_{\mathrm{IC}}$ & $\Phi_{\mathrm{F}} \times 10^{-3}$ & ${ }^{3} \Phi$ & $\Phi_{\mathrm{IC}}$ \\
\hline $1 \mathrm{AF}$ & 55 & 0.86 & 0.09 & 57 & 0.89 & 0.05 & 68 & 0.79 & 0.14 \\
\hline 1MAF & 65 & 0.63 & 0.31 & 65 & 0.62 & 0.32 & 64 & 0.55 & 0.39 \\
\hline 1DMAF & 2.4 & 0.00 & $>0.99$ & $2.7^{a}$ & 0.00 & $>0.99$ & 4 & 0.00 & $>0.99$ \\
\hline $2 \mathrm{AF}$ & 1.0 & 0.02 & 0.98 & $b$ & 0.00 & 1.00 & $b$ & 0.00 & 1.00 \\
\hline 2MAF & 1.0 & $<0.02$ & $>0.98$ & $b$ & 0.00 & 1.00 & $b$ & 0.00 & 1.00 \\
\hline 2DMAF & 1.1 & $<0.02$ & $>0.98$ & $b$ & 0.00 & 1.00 & $b$ & 0.00 & 1.00 \\
\hline $3 \mathrm{AF}$ & 160 & 0.26 & 0.58 & 43 & 0.08 & 0.88 & $3.3^{a}$ & $<0.01$ & $>0.99$ \\
\hline 3MAF & 250 & 0.19 & 0.56 & 64 & 0.08 & 0.86 & $6.5^{a}$ & $\leqslant 0.01$ & $>0.99$ \\
\hline 3DMAF & 280 & 0.11 & 0.61 & 83 & 0.06 & 0.86 & $8.1^{a}$ & $\leqslant 0.01$ & $>0.99$ \\
\hline $4 \mathrm{AF}$ & 80 & 0.48 & 0.44 & 12 & 0.07 & 0.92 & $0.24^{a}$ & $\leqslant 0.01$ & $>0.99$ \\
\hline 4MAF & 77 & 0.19 & 0.73 & 5.1 & 0.07 & 0.92 & $0.14^{a}$ & $\leqslant 0.01$ & $>0.99$ \\
\hline 4DMAF & 91 & 0.37 & 0.54 & 7.5 & 0.05 & 0.94 & $0.27^{a}$ & $\leqslant 0.01$ & $>0.99$ \\
\hline
\end{tabular}

Table 2 Quantum yield of processes depopulating the singlet excited state in various solvents at $295 \mathrm{~K}$ 
Table 3 Energy of excited states, fluorescence lifetimes and rate constants of radiationless processes for aminofluorenones in various solvents

\begin{tabular}{|c|c|c|c|c|c|c|}
\hline & Solvent & $10^{-3} E\left(\mathrm{~S}_{1}\right)^{a} / \mathrm{cm}^{-1}$ & $10^{-3} E\left(\mathrm{~T}_{1}\right)^{b} / \mathrm{cm}^{-1}$ & $\tau_{\mathrm{F}} / \mathrm{ns}$ & $10^{-7} k_{\mathrm{ISC}} / \mathrm{s}^{-1}$ & $10^{-7} k_{\mathrm{IC}} / \mathrm{s}^{-1}$ \\
\hline \multirow[t]{3}{*}{$1 \mathrm{AF}$} & Toluene & 22.1 & \multirow[t]{3}{*}{16.9} & 1.3 & 66 & 6.9 \\
\hline & Acetonitrile & 21.6 & & 2.2 & 40 & 2.3 \\
\hline & Ethanol & 21.0 & & $4.0^{a, c}$ & 20 & 3.5 \\
\hline \multirow[t]{3}{*}{$1 \mathrm{MAF}$} & Toluene & 20.7 & \multirow[t]{3}{*}{16.1} & 2.8 & 23 & 11 \\
\hline & Acetonitrile & 20.4 & & 2.9 & 21 & 11 \\
\hline & Ethanol & 20.1 & & 2.8 & 20 & 14 \\
\hline \multirow[t]{2}{*}{ 1DMAF } & Toluene & 20.6 & \multirow[t]{7}{*}{17.0} & $2.2^{a, c}$ & $<0.5$ & 45 \\
\hline & Acetonitrile & 20.3 & & $2.8^{a, c}$ & $<0.5$ & 36 \\
\hline \multirow[t]{2}{*}{$2 \mathrm{AF}$} & Toluene & \multirow[t]{2}{*}{18.7} & & \multirow[t]{2}{*}{0.8} & \multirow[t]{2}{*}{2.5} & \multirow[t]{2}{*}{122} \\
\hline & Acetonitrile & & & & & \\
\hline \multirow[t]{2}{*}{$2 \mathrm{MAF}$} & Toluene & \multirow[t]{2}{*}{17.7} & & \multirow[t]{2}{*}{$0.63^{a}$} & \multirow[t]{2}{*}{$<3.1$} & \multirow[t]{2}{*}{156} \\
\hline & Acetonitrile & & & & & \\
\hline 2DMAF & $\begin{array}{l}\text { Toluene } \\
\text { Acetonitrile }\end{array}$ & 17.2 & & $0.79^{a}$ & $<2.5$ & 126 \\
\hline \multirow[t]{2}{*}{$3 \mathrm{AF}$} & Toluene & 21.9 & \multirow[t]{2}{*}{16.1} & 13.9 & 1.9 & 4.2 \\
\hline & Acetonitrile & 20.8 & & 4.2 & 1.9 & 21 \\
\hline \multirow[t]{2}{*}{$3 \mathrm{MAF}$} & Toluene & 21.5 & \multirow[t]{2}{*}{16.3} & 12.4 & 1.5 & 4.5 \\
\hline & Acetonitrile & 20.5 & & 5.6 & 1.4 & 16 \\
\hline \multirow[t]{2}{*}{ 3DMAF } & Toluene & 21.0 & \multirow[t]{2}{*}{15.9} & 13.3 & 0.83 & 4.6 \\
\hline & Acetonitrile & 20.0 & & 5.5 & 1.1 & 16 \\
\hline \multirow[t]{2}{*}{$4 \mathrm{AF}$} & Toluene & 20.3 & & 10.1 & 4.8 & 4.4 \\
\hline & Acetonitrile & 19.0 & & 3.3 & 2.1 & 28 \\
\hline \multirow[t]{2}{*}{$4 \mathrm{MAF}$} & Toluene & 19.3 & & 10.2 & 1.9 & 7.2 \\
\hline & Acetonitrile & 18.1 & & 2.2 & 3.2 & 42 \\
\hline \multirow[t]{2}{*}{ 4DMAF } & Toluene & 19.6 & & 12.4 & 3.0 & 4.4 \\
\hline & Acetonitrile & 18.5 & & 2.7 & 1.9 & 35 \\
\hline
\end{tabular}

${ }^{a}$ Ref. 21. ${ }^{b}$ Measured in 2-methyltetrahydrofuran at $77 \mathrm{~K} .{ }^{c}$ The longer component of the two exponential decay.

dominant transition from the singlet excited state, energy dissipation via intramolecular hydrogen bonding can not be a significant process.

\subsection{Rate constants of triplet formation}

To reveal how the molecular structure variation affects the competition between the nonradiative energy dissipation channels, the rate constants for intersystem crossing $\left(k_{\mathrm{ISC}}\right)$ and internal conversion $\left(k_{\mathrm{IC}}\right)$ were derived using the expressions given below:

$$
\begin{gathered}
k_{\mathrm{ISC}}=\Phi_{\mathrm{ISC}} / \tau_{\mathrm{F}} \\
k_{\mathrm{IC}}=\left(1-\Phi_{\mathrm{ISC}}-\Phi_{\mathrm{F}}\right) / \tau_{\mathrm{F}}
\end{gathered}
$$

Table 3 demonstrates that the short fluorescence lifetime $\left(\tau_{\mathrm{F}}\right)$ of $1 \mathrm{AF}$ and $1 \mathrm{MAF}$ is attributed to the fast intersystem crossing whose rate is about one order of magnitude higher than that of the other aminofluorenones. The $\tau_{\mathrm{F}}$ and $k_{\mathrm{ISC}}$ values exhibit opposite solvent dependence which indicates that the increase of the $1 \mathrm{AF}$ fluorescence lifetime with increasing solvent polarity results from the decrease of the rate constant of triplet formation. This solvent effect and the much higher $k_{\text {ISC }}$ for $1 \mathrm{AF}$ and $1 \mathrm{MAF}$ compared with that of the other aminofluorenones can be rationalized by considering the results obtained in previous studies ${ }^{3,9}$ of the photophysics of fluorenone. It was shown that the intersystem crossing from the lowest excited singlet state of fluorenone occurs via two processes: a thermally activated transition to the adjacent $\mathrm{T}_{n}\left(\mathrm{n} \pi^{*}\right)$ state and a temperature independent transition to the low-lying $\mathrm{T}_{1}\left(\pi \pi^{*}\right)$ and $\mathrm{T}_{2}\left(\pi \pi^{*}\right)$ states. ${ }^{9}$ We find that the photophysical characteristics of aminofluorenones do not show significant temperature dependence. For example, the fluorescence lifetimes at $217 \mathrm{~K}(1.6,13.6$ and $11.8 \mathrm{~ns}$ for $1 \mathrm{AF}$, $3 \mathrm{AF}$ and $4 \mathrm{AF}$, respectively) were very close to the values obtained at room temperature (Table 3). This indicates that triplet formation does not undergo via a thermally enhanced $\mathrm{S}_{1}\left(\pi \pi^{*}\right) \rightarrow \mathrm{T}_{n}\left(\mathrm{n} \pi^{*}\right)$ process. Electron donating substituents are known to lower $\pi \pi^{*}$ and raise $n \pi^{*}$ transition energies, ${ }^{25}$ thus the introduction of $-\mathrm{NH}_{2}$ and $-\mathrm{NHCH}_{3}$ groups into the fluo- renone moiety increases the $\mathrm{S}_{1}\left(\pi \pi^{*}\right)-\mathrm{T}_{n}\left(\mathrm{n} \pi^{*}\right)$ energy difference. As a result of that, the $S_{1}\left(\pi \pi^{*}\right)-T_{n}\left(n \pi^{*}\right)$ energy gap becomes so large that thermal activation is not able (around room temperature) to bring about the transition between these states. Consequently, triplet formation can occur only via temperature independent transitions to lower-lying triplet states.

Theoretical calculations ${ }^{26}$ have shown that only one $\pi \pi^{*}$ triplet state has lower energy than that of the lowest excited singlet state for $2 \mathrm{AF}$ and $4 \mathrm{AF}$; however, both the $\mathrm{T}_{1}\left(\pi \pi^{*}\right)$ and $\mathrm{T}_{2}\left(\pi \pi^{*}\right)$ states are located below the $\mathrm{S}_{1}\left(\pi \pi^{*}\right)$ state for $3 \mathrm{AF}$. It is especially noteworthy that, for $1 \mathrm{AF}$, a third $\pi \pi^{*}$ state appears below the energy of the lowest excited singlet state but in its immediate vicinity. The rapid intersystem crossing for $1 \mathrm{AF}$ and $1 \mathrm{MAF}$ probably arises from the efficient interaction between the close-lying $\mathrm{S}_{1}\left(\pi \pi^{*}\right)$ and $\mathrm{T}_{3}\left(\pi \pi^{*}\right)$ states. The solvent effect on the $k_{\text {ISC }}$ of $1 \mathrm{AF}$ indicates that mixing between the adjacent $S_{1}\left(\pi \pi^{*}\right)$ and $S_{2}\left(n \pi^{*}\right)$ states may play an important role as well. It is well established that the two lowest excited singlet states of fluorenone are in close proximity ${ }^{3}$ and the relative position of these states exerts a profound effect on the intersystem crossing rate. ${ }^{10}$ Since the $S_{1}$ energy is similar for $1 \mathrm{AF}$ and fluorenone, ${ }^{21}$ the $\mathrm{S}_{2}\left(\mathrm{n} \pi^{*}\right)$ state of $1 \mathrm{AF}$ probably remains in the vicinity of $S_{1}\left(\pi \pi^{*}\right)$ state in non-polar solvents and the mixing between these states can promote the fast intersystem crossing. Going to more polar media enlarges the $\mathrm{S}_{1}\left(\pi \pi^{*}\right)-\mathrm{S}_{2}\left(\mathrm{n} \pi^{*}\right)$ energy gap and, thereby, diminishes the spinorbit coupling with triplet $\pi \pi^{*}$ states. This effect explains the continuous decrease of $k_{\text {ISC }}$ with increasing solvent polarity for $1 \mathrm{AF}$ (Table 3). Methylation of the amino-group shifts the $\mathrm{S}_{1}\left(\pi \pi^{*}\right)$ level toward lower energies and expands the $\mathrm{S}_{1}\left(\pi \pi^{*}\right)-\mathrm{S}_{2}\left(\mathrm{n} \pi^{*}\right)$ energy gap so much that no mixing can occur. Therefore, the rate constant of triplet $1 \mathrm{MAF}$ formation does not depend on the solvent.

Intersystem crossing rate constants of 2-, 3- and 4aminofluorenones are much smaller and do not vary significantly with molecular structure and solvent. These facts can be rationalized based on the results of our semiempirical calculations (vide supra). Since no triplet state is located in the neighborhood of the lowest excited singlet state in these com- 
pounds, the larger S-T energy gap leads to slower triplet formation.

\subsection{Rate constants of internal conversion}

We have recently shown ${ }^{18}$ that the variation of the internal conversion rate constant $\left(k_{\mathrm{IC}}\right)$ for various 2 -substituted fluorenone derivatives can be rationalized in terms of the energy gap law which is expressed in quantitative form by the equation $^{27,28}$

$$
k_{\mathrm{IC}}=\frac{C^{2}(2 \pi)^{1 / 2}}{h\left(\Delta E h \omega_{\mathrm{M}}\right)^{1 / 2}} \exp \left(-\frac{\gamma \Delta E}{h \omega_{\mathrm{M}}}\right)
$$

where

$$
\gamma=\ln \left(\frac{2 \Delta E}{h \omega_{\mathrm{M}} d \Delta_{\mathrm{M}}^{2}}\right)-1
$$

$\Delta E$ represents the energy gap between the excited and ground electronic states, $C$ is the electronic coupling matrix element; $h \omega_{\mathrm{M}}$ is the energy of the accepting vibrational mode that has $d$ degeneracy and $\Delta_{\mathrm{M}}^{2}$ reduced displacement. The term $\gamma$ is considered a constant because it is a weakly varying function of $\Delta E$.

The $k_{\text {IC }}$ values listed in Table 3 exhibit considerable change with molecular structure and solvent polarity. Fig. 4 presents the plot of the logarithm of the internal conversion rate constants in toluene against the energy of the lowest excited singlet states $\left(E\left(\mathrm{~S}_{1}\right)\right)$. The open circles represent the data for 2-substituted fluorenones taken from our previous paper, ${ }^{18}$ whereas filled circles display the results of this work. The $k_{\text {IC }}$ values for $1 \mathrm{AF}, 1 \mathrm{MAF}, 3 \mathrm{AF}, 3 \mathrm{MAF}$ and $3 \mathrm{DMAF}$ fit well to the linear correlation found for 2-substituted fluorenones. This indicates that the deactivation of these compounds from the $\mathrm{S}_{1}$ state probably takes place via a common dominant accepting vibrational mode. However, the internal conversion is slower for 4AF, 4MAF, 4DMAF and faster for 1DMAF than is predicted by the energy gap law. The deviation suggests that the electronic coupling matrix element $(C$ in eqn. (5)) and the major energy dissipating vibrations (i.e., $h \omega_{\mathrm{M}}$ ) of these derivatives differ from those of the other fluorenones. The rapid internal conversion of 1DMA is probably related to the torsion of the dimethylamino substituent. Semiempirical calculations ${ }^{21}$ showed that the methyl groups are only slightly tilted relative to the plane of the fluorenone skeleton in the ground state but they favor perpendicular conformation in the $\mathrm{S}_{1}$ state. This suggests that rotation of the $\left(\mathrm{CH}_{3}\right)_{2} \mathrm{~N}-$ moiety is involved in the deactivation of the excited state. The fact that phosphorescence can be detected at $77 \mathrm{~K}$ in spite of the negligible triplet yield at room temperature also strongly supports the involvement of the rotation of the dimethylamino group in the internal conversion. The blocking of the substituent

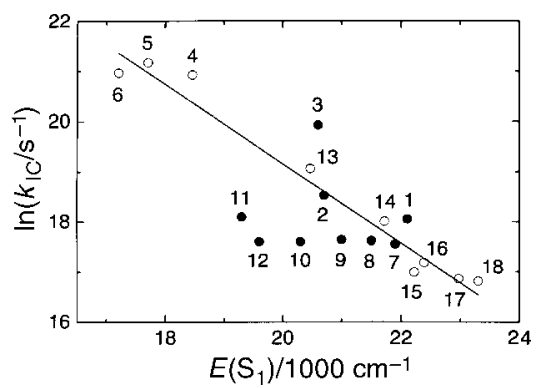

Fig. 4 Plot of $\ln k_{\mathrm{IC}} v s$. the energy of the lowest excited singlet state for various fluorenone derivatives in toluene. 1AF (1), 1MAF (2), 1DMAF (3), 2AF (4), 2MAF (5), 2DMAF (6), 3AF (7), 3MAF (8), 3DMAF (9), 4AF (10), 4MAF (11), 4DMAF (12), 2- $\mathrm{CH}_{3} \mathrm{O}$-fluorenone (13), 2- $\mathrm{CF}_{3} \mathrm{CONH}$-fluorenone (14), 2-fluorofluorenone (15), 3azafluorenone (16), fluorenone (17), 2- $\mathrm{CH}_{3} \mathrm{OOC}$-fluorenone (18). Open circles represent the data for unsubstituted and 2-substituted compounds. motion in organic glass at $77 \mathrm{~K}$ slows down the radiationless deactivation to the ground state and thereby, facilitates the competition of triplet formation. The slope $\left(-\gamma / h \omega_{\mathrm{M}}=-8.1\right.$ $\left.\times 10^{-4} \mathrm{~cm}\right)$ and the intercept $\left(\ln \left(C^{2}(2 \pi)^{1 / 2}\right) / h\left(\Delta E h \omega_{\mathrm{M}}\right)^{1 / 2}=\right.$ $35.5)$ of the straight line shown in Fig. 4 are close to those reported for carotenoids, compounds which have extended $\pi$ electron conjugation. ${ }^{29}$

Fig. 5 shows that the internal conversion rate constants of aminofluorenones in acetonitrile fit the $\ln k_{\mathrm{IC}} v s . E\left(\mathrm{~S}_{1}\right)$ linear correlation obtained for 2-substituted fluorenones in toluene. The dotted line indicates the best fit of data obtained for 4aminofluorenones in toluene and acetonitrile (slope $=$ $-1.2 \times 10^{-3} \mathrm{~cm}$, intercept $=42$ ). Based on Figs. 4 and 5 , we can conclude that the differences between $k_{\text {IC }}$ values obtained in toluene and acetonitrile (Table 3) can be explained in terms of the energy gap law. The change of dipole moment upon excitation to the lowest excited singlet state is relatively small $(\Delta \mu=3.5 \mathrm{D} \text { for } 1 \mathrm{AF})^{19}$ for 1 -substituted derivatives, hence, the interaction with the solvents slightly influences the excited state energy. The third column in Table 3 shows that $E\left(\mathrm{~S}_{1}\right)$ of 1-aminofluorenones is only $c a$. $300-500 \mathrm{~cm}^{-1}$ lower in acetonitrile than in toluene, whereas a much larger (1000-1300 $\mathrm{cm}^{-1}$ ) change is seen for the rest of the compounds. In the former case the small solvent effect on the excited state energy results in a slight change in the internal conversion rates. However, interaction with polar solvents, such as acetonitrile, decreases the singlet excited state energy of 2-, 3- and 4aminofluorenones to a larger extent and the vibrational coupling enhancement caused thereby leads to a substantial increase in $k_{\mathrm{IC}}$.

Finally, we should comment on the effect of ethanol upon the yield of internal conversion (Table 2). Internal conversion of the aminofluorenones substituted in the 2-, 3- and 4- position is accelerated in ethanol insomuch that it becomes the prevailing process depopulating the singlet excited state. However, in the cases of $1 \mathrm{AF}$ and $1 \mathrm{MAF}$, ethanol has little impact on $k_{\text {IC }}$ (Table 3) and triplet formation remains the dominant photophysical process (Table 2). The characteristic difference in the behavior of these groups of compounds originates from the dissimilar excited state dipole moments. The dipole moment changes upon excitation to the $\mathrm{S}_{1}$ state $(\Delta \mu)$ are $3.5 \mathrm{D},{ }^{19} 4.9 \mathrm{D},{ }^{19} 5.2 \mathrm{D}^{21}$ and $>5.5 \mathrm{D}$ (the value reported

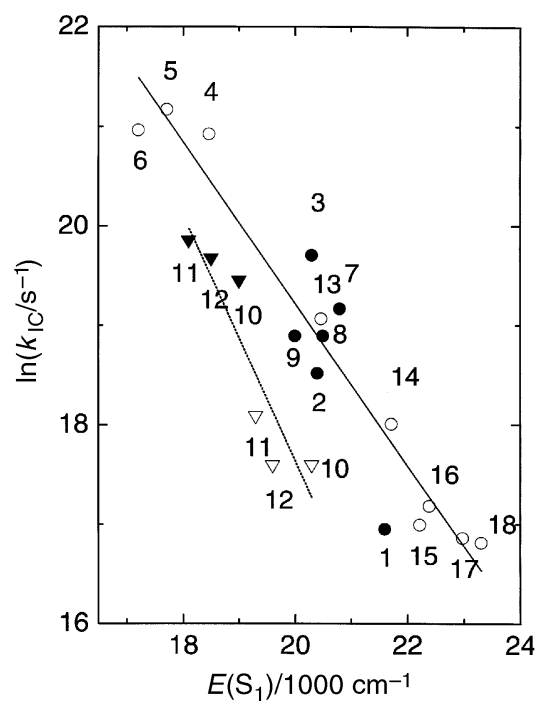

Fig. 5 Plot of $\ln k_{\mathrm{IC}} v s$. the energy of the lowest excited singlet state for various aminofluorenones in acetonitrile (filled symbols), unsubstituted and 2-substituted fluorenones in toluene (open circles), and 4-aminofluorenones both in toluene (open triangles) and in acetonitrile (filled triangles). 1AF (1), 1MAF (2), 1DMAF (3), 2AF (4), 2MAF (5), 2DMAF (6), 3AF (7), 3MAF (8), 3DMAF (9), 4AF (10), $4 \mathrm{MAF}$ (11), 4DMAF (12), 2- $\mathrm{CH}_{3} \mathrm{O}$-fluorenone (13), 2- $\mathrm{CF}_{3} \mathrm{CONH}$ fluorenone (14), 2-fluorofluorenone (15), 3-azafluorenone (16), fluorenone (17), 2- $\mathrm{CH}_{3} \mathrm{OOC}$-fluorenone (18). 
for $2-\mathrm{CF}_{3} \mathrm{CONH}$-fluorenone ${ }^{18}$ for $1 \mathrm{AF}, 3 \mathrm{AF}, 4 \mathrm{AF}$ and $2 \mathrm{AF}$, respectively. The large $\Delta \mu$ values for the latter three compounds indicate that the conjugation of the lone electron pair of the nitrogen leads to a more pronounced charge shift toward the carbonyl group. The increase of the negative charge density on the carbonyl oxygen promotes hydrogen bonding. Since the vibrations associated with hydrogen bonding can act as effective accepting modes in the radiationless deactivation, ${ }^{30}$ the strengthening of the hydrogen bond with ethanol results in a higher internal conversion rate. In contrast, the singlet excited state of $1 \mathrm{AF}$ and $1 \mathrm{MAF}$ have smaller charge transfer character; hence, the relatively low electron density on the carbonyl oxygen permits weak hydrogen bonding. Therefore, going from aprotic to protic solvents does not affect significantly the internal conversion rate of these two compounds.

\section{Acknowledgements}

We very much appreciate the support of this work by the Hungarian Science Foundation (OTKA, Grant T034990) and the bilateral program between the Japanese Society for the Promotion of Science and the Hungarian Academy of Sciences.

\section{References}

1 K. Yoshihara and D. R. Kearns, J. Chem. Phys., 1966, 45, 1991

2 A. Kuboyama, Bull. Chem. Soc. Jpn., 1964, 37, 1540.

3 T. Kobayashi and S. Nagakura, Chem. Phys. Lett., 1976, 43, 429.

4 L. J. Andrews, A. Deroulede and H. Linschitz, J. Phys. Chem., $1978,82,2304$

5 J. B. Guttenplan and S. G. Cohen, Tetrahedron Lett., 1969, 2125.

6 R. A. Caldwell, Tetrahedron Lett., 1969, 2121.

7 (a) A. A. Lamola and G. S. Hammond, J. Chem. Phys., 1965, 43, 2129; (b) R. A. Caldwell and R. P. Gajewski, J. Am. Chem. Soc., 1971, 93, 533; (c) T. Fujii, M. Sano, S. Mishima and H. Hiratsuka, Bull. Chem. Soc. Jpn., 1996, 69, 1833.

8 (a) S. J. Weininger, Y. Ren, Z. Wang, L. Chen and W. G. McGimpsey, J. Phys. Chem. A, 1999, 103, 5477; (b) R. S. Murphy, C. P. Moorlag, W. H. Green and C. Bohne, J. Photochem. Photobiol. A: Chem., 1997, 110, 123.
9 L. Biczók and T. Bérces, J. Phys. Chem., 1988, 92, 3842

10 L. Biczók, T. Bérces and F. Márta, J. Phys. Chem., 1993, 97, 8895.

11 P. A. Thompson and J. D. Simon, J. Am. Chem. Soc., 1993, 115 5657.

12 P. A. Thompson and J. D. Simon, J. Chem. Phys., 1992, 97, 4792.

13 L. Biczók, L. Jicsinszky and H. Linschitz, J. Inclusion Phenom. Mol. Recognit. Chem., 1994, 18, 237.

14 L. Biczók, L. Jicsinszky and H. Linschitz, Proceedings of the Eighth International Symposium on Cyclodextrins, ed. J. Szejtli and L. Szente, Kluwer Academic, Dordrecht, 1996, p. 255.

15 T. Yatsuhashi, Y. Nakajima, T. Shimada, H. Tachibana and H. Inoue, J. Phys. Chem. A, 1998, 102, 8657.

16 T. Yatsuhashi and H. Inoue, J. Phys. Chem. A, 1997, 101, 8166.

17 L. Biczók, T. Bérces and H. Linschitz, J. Am. Chem. Soc., 1997, 119, 11071.

18 L. Biczók and T. Bérces and H. Inoue, J. Phys. Chem. A, 1999, 103, 3837.

19 R. S. Moog, N. A. Burozski, M. M. Desai, W. R. Good, C. D Silvers, P. A. Thompson and J. D. Simon, J. Phys. Chem., 1991, 95, 8466.

20 P. A. Thompson, A. E. Broudy and J. D. Simon, J. Am. Chem Soc., 1993, 115, 1925.

21 T. Yatsuhashi, Y. Nakajima, T. Shimada and H. Inoue, J. Phys. Chem. A, 1998, 102, 3018.

22 C. Huggenberger and H. Labhart, Helv. Chim. Acta, 1978, 61, 250.

23 S. L. Murov, G. L. Carmichael and I. Hug, Handbook of Photochemistry, Marcel Dekker, New York, 2nd edn., 1993.

24 V. Wintgens, P. Valat, J. Kossanyi, L. Biczók, A. Demeter and T. Bérces, J. Chem. Soc., Faraday Trans., 1994, 90, 411.

25 P. J. Wagner and E. J. Siebert, J. Am. Chem. Soc., 1981, 103, 7329.

26 The geometry of the molecule was optimized by PM3 calculation and the energy levels were obtained by $\mathrm{CNDO} / \mathrm{S} 3$ method. The calculated energy of the first singlet excited states agreed with the data observed experimentally in cyclohexane: 1AF (calcd. $2.53 \times 10^{4} \mathrm{~cm}^{-1}$, obs. $2.28 \times 10^{4} \mathrm{~cm}^{-1}$ ), $2 \mathrm{AF}$ (calcd. $2.11 \times 10^{4}$ $\mathrm{cm}^{-1}$, obs. $1.97 \times 10^{4} \mathrm{~cm}^{-1}$ ), 3AF (calcd. $2.25 \times 10^{4} \mathrm{~cm}^{-1}$, obs. $2.30 \times 10^{4} \mathrm{~cm}^{-1}$ ), 4 AF (calcd. $2.20 \times 10^{4} \mathrm{~cm}^{-1}$, obs. $2.14 \times 10^{4}$ $\left.\mathrm{cm}^{-1}\right)$

27 R. Englman and J. Jortner, Mol. Phys., 1970, 18, 145

28 K. F. Freed and J. Jortner, J. Chem. Phys., 1970, 52, 6272.

29 H. A. Frank, R. Gebhard, J. Lugtenburg, D. Gosztola and M. R. Wasielewski, Chem. Phys. Lett., 1993, 207, 88

30 H. Inoue, M. Hida, N. Nakashima and K. Yoshihara, J. Phys. Chem., 1982, 86, 3184. 